See discussions, stats, and author profiles for this publication at: https://www.researchgate.net/publication/345387390

\title{
Simplified Model to Represent the Installation Process of Subsea Equipments
}

Conference Paper · October 2020

DOI: 10.17648/sobena-2020-122990

5 authors, including:

Emerson Andrade

Federal University of Rio de Janeiro

5 PUBLICATIONS 1 CITATION

SEE PROFILE

Joel Sales Junior

Federal University of Rio de Janeiro

27 PUBLICATIONS 45 CITATIONS

SEE PROFILE

Some of the authors of this publication are also working on these related projects:

Advanced analysis of vortex induced vibration in Subsea Jumpers View project

Investigation the effects of waves on Ship's structure considering the Hydroelasticity effects View project 


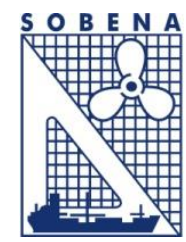

\title{
28을 Congresso Internacional de Transporte Aquaviário, Construção Naval e Offshore
}

\author{
Rio de Janeiro/RJ, 19-21 de outubro de 2020 \\ Simplified Model to Represent the Installation Process of Subsea \\ Equipments
}

\begin{abstract}
Filipe Salvador Lopes, UFRJ/COPPE, Rio de Janeiro/Brasil, filipe salvador@oceanica.ufri.br Antonio Carlos Fernandes, UFRJ/COPPE, Rio de Janeiro/Brasil, acfernandes@oceanica.ufrj.br Emerson Martins de Andrade, UFRJ/COPPE, Rio de Janeiro/Brasil, mrsonandrade@oceanica.ufri.br Joel Sena Sales Junior, UFRJ/COPPE, Rio de Janeiro/Brasil, joel@oceanica.ufrj.br Rodrigo Klim Gomes, UFRJ/COPPE, Rio de Janeiro/Brasil, rklim@oceanica.ufri.br
\end{abstract}

\begin{abstract}
During the installation of a subsea module it is extremely important to guarantee that the structure will not be damaged, as this would imply in elevated costs and hazards to the environment. In order to minimize these risks, the installation process can be simulated inside software that use numerical modeling by considering different environmental conditions, so that a safer procedure with more adequate operational window can be achieved. However, these software can be very expensive, and this kind of simulations usually takes a long time, making it very convenient when one has access to a simplified model, capable of simulating different conditions in a short period of time, while still providing reliable results. This paper presents a simplified model developed in Python programming language, which uses a fourth-order RungeKutta method to solve the equation of motions that governs a vertical installation process. The installation ship's motions were applied to the top of the cable, simulating its connection to a crane aboard, and then the motions of the suspended equipment and the cable tension could be calculated. The results obtained through the use of this simplified model were then compared to the ones obtained through the use of a much more complex model using the OrcaFlex ${ }^{\circledR}$ software and to experimental data.
\end{abstract}

\section{Introduction}

An equipment such as an offshore manifold is a very expensive module, composed by a set of valves and accessories, which is responsible for directing the production of different oil wells to a pipeline that conducts all the production to the Production Unit. This equipment is also responsible for distributing water and gas injection from the Production Unit to the wells.

Its installation process must be very well planned in order to avoid any damage to the structure, as this would imply in elevated costs. There are different ways to install it, as examples, the pencil buoy method (Mork \& Lunde, 2007) or the pendular method (Roveri et al., 2005) for ultradeep waters. This work focuses in an installation process in which the manifold is installed vertically from a ship by a crane. Regardless of the chosen method, simulating the installation process usually requires the use of complex and expensive software, resulting in simulations that take a long time to be completed.

Moreover, at the stage of definition of the installation procedure, one may find that the safe operational window is too tight for the chosen procedure (Roveri et al., 2005). 
This kind of issue could be avoided or diminished if one considered installation characteristics during a sooner stage of the design of the equipment, so that some of the mechanical and hydrodynamic variables could still be tunable in order to improve installation characteristics. Having this in mind, a tool that allowed fast and precise simulations could be used on design stage to help on the screening of parameters such as added mass, damping and cable stiffness, so that safety operation windows could be enlarged.

So, this work aimed to develop a simplified, but still reliable, model to simulate the dynamics of the installation under different environmental conditions.

The simplified model was developed on Python programming language, and uses a fourth order Runge-Kutta method to solve the equation of motions that governs the installation process. The results obtained by the simplified model are then compared to results obtained by a complete model constructed on OrcaFlex software and also to experimental data obtained on model tests (Andrade et al., 2020). The following sections show the theoretical background of the model and the comparison results obtained so far.

\section{Physical Background}

\subsection{Equation of Motions}

The first step to make the simplified model is to understand the physics behind the problem. It is being considered that there is no excitation force being applied directly to the manifold. Instead, there are waves exciting the ship responsible for the installation process. For the sake of simplicity, it was considered that the ship's motions are the same of the crane. There is a cable connected to the manifold and to the crane, which will act as a spring whenever it is stretched. Therefore, this problem can be modeled as a mass-spring-damper system in which the manifold and its added mass represent the mass, the cable is the spring and the damping is due to the viscous and drag effects of the interaction between the equipment and the water. The waves can be represented as causing a harmonic movement on the base of the system, which is the top of the cable, connected to the crane. The problem can be modeled as shown in Figure 1.

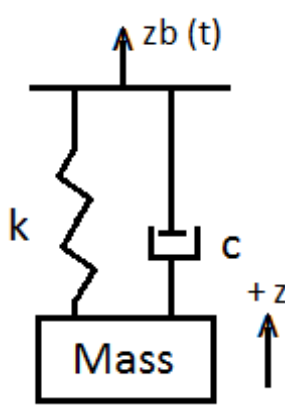

Free Body Diagram

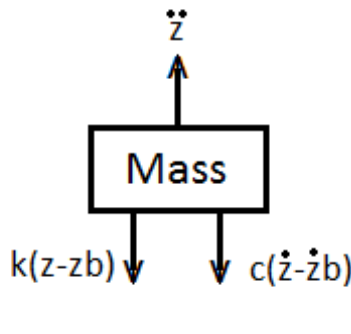

Figure 1 - Free Body Diagram of the problem

It is important to notice that the weight does not appear in the free body diagram because it is considered that the problem starts in a static equilibrium position, in which the cable is already stretched, resulting in an initial elastic force with the same intensity and direction, but opposite sense, of the weight. Applying Newton's second law and rearranging the terms, it is possible to obtain Equation 1, as presented by Rao (2009).

$$
m \ddot{z}+c\left(\dot{z}-\dot{z}_{b}\right)+k\left(z-z_{b}\right)=0
$$

Where $m$ is the mass, $c$ is the damping coefficient and $k$ is the spring stiffness. The velocity $\dot{z}$ is represented as the first derivative of the position $z$, and the acceleration $\ddot{z}$ as the second derivative of the position $z$. The index $b$ represents the baseline motions.

\subsection{Hydrodynamic Forces}

Equation 1 is a good way to represent the problem, however, this work focuses on simulating conditions in which the manifold is underwater. Therefore, there will be hydrodynamic forces that must be considered in order to properly represent the installation process. These forces will be represented through the use of Morison's equation, as presented by Journée and Massie (2001), which is a combination of an inertial term and a drag term.

$$
\begin{gathered}
F(t)=F_{\text {Inertia }}(t)+F_{\text {Drag }}(t) \\
F_{\text {Inertia }}(t)=\rho C_{a} V_{P} \ddot{z}(t) \\
F_{\text {Drag }}(t)=\frac{1}{2} \rho C_{d} A_{P}|\dot{z}(t)| \dot{z}(t)
\end{gathered}
$$

Where $\rho$ is the density of water, $C_{a}$ is the added mass coefficient, $V_{P}$ is the prismatic volume of the manifold, $C_{d}$ is the drag coefficient and $A_{P}$ is the projected area. Applying Equations 3 and 4 in Equation 1, it is possible to obtain the following equation. 


$$
\begin{aligned}
& \left(m+\rho C_{a} V_{P}\right) \ddot{z} \\
& +\frac{1}{2} \rho C_{d} A_{P}\left|\dot{z}-\dot{z}_{b}\right|\left(\dot{z}-\dot{z}_{b}\right) \\
& +k\left(z-z_{b}\right)=0
\end{aligned}
$$

Equation 5 is the equation of motions of the manifold, in which the hydrodynamic forces of added mass and drag are considered due to the fact that the manifold is underwater. This is the equation that will be solved by the fourth order Runge-Kutta method, presented in the next section.

\section{Simplified Model}

\subsection{Assumptions}

The fourth order Runge Kutta method is applied to Equation 5 in order to obtain the variation of the position and the velocity of the manifold for each time step. However, this is only possible if every other term of the equation is known.

In order to precisely predict the motions on the top of the cable, connected to the crane, it would be necessary to have the ship's Response Amplitude Operators (RAO). As this is usually not the case at very early design stages, the present model works only with frequency and amplitude ranges for the vertical motions on the cable top, due to the ship's heave, as the heave motion's amplitude varies with the wave frequency. Depending on the frequency, the motions can be amplified, lessened or even the same as the wave amplitude. The heave motion's amplitude and frequency are then assumed to be equal to the wave amplitude and frequency, respectively. Therefore, the motions on the top of the cable are modeled as a sine function, and the velocity as its first time-derivative, as shown in Equations 6 and 7.

$$
\begin{gathered}
z_{b}(t)=A_{w} \sin (\omega t) \\
\dot{z}_{b}(t)=\omega A_{w} \cos (\omega t)
\end{gathered}
$$

In which $A_{w}$ is the wave amplitude (or heave amplitude) and $\omega$ is the wave frequency. A time ramp is applied to the motion, by considering the motion's amplitude at the beginning of the simulation as $10 \%$ of the final amplitude and after each full cycle it increases by another $10 \%$, until it reaches the same value of the wave amplitude, which is kept until the end of the simulation. A full cycle is considered to have the same length of time as the wave period.
It is also assumed that the cable will work as a spring whenever it is stretched, i.e. whenever its instantaneous length is larger than its initial length. The cable axial stiffness is calculated as shown in Equation 8.

$$
k=\frac{E A}{L}
$$

In which $E$ is the elastic modulus, $A$ is the crosssectional area and $L$ is the cable's length, which are all given data. As explained in Section 2.1, the manifold's weight does not appear in the equation of motions because it is assumed that the simulation begins in a static equilibrium condition, in which the cable is already stretched to compensate the manifold's underwater weight, as can be seen in Equation 9.

$$
\Delta L=\frac{m g-\rho \nabla g}{k}
$$

In which $\nabla$ is the manifold's real volume and $g$ is the gravity's acceleration. It is the possible to recalculate the cable's axial stiffness due to its new length, as shown in Equation 10.

$$
k^{\prime}=\frac{E A}{(L+\Delta L)}
$$

During the simulations, the cable length will vary due to the motions on the top of the cable and on the manifold. Therefore, its axial stiffness can be recalculated in each time step considering its instantaneous length at that given time. This correction is usually negligible, but it is calculated in order to ensure a better representation of the problem.

As previously stated, the cable is assumed to work as a spring whenever it is stretched. However, when its instantaneous length is lesser than its initial length the cable will not work as a compressed spring, as it is assumed that its force will be equal to zero, as shown in Equation 22. It is also important to notice that the cable's mass, added mass and drag were not considered in the model.

\subsection{Model}

With the assumptions presented in Section 3.1, it is then possible to apply the fourth order RungeKutta method to solve Equation 5. As presented by Mariano (1998), it is necessary to calculate four coefficients in order to obtain the increment in 
position and another four to calculate the increment in velocity. Rearranging Equation 5, considering that the acceleration is the first derivative of the velocity and applying the RungeKutta method, the following equations are obtained.

$$
\begin{aligned}
& \begin{array}{c}
k_{1}=\dot{z} d t \\
l_{1}=\frac{d t}{\left(m+\rho C_{a} V_{P}\right)}\left(-\frac{1}{2} \rho C_{d} A_{P} \mid \dot{z}\right.
\end{array} \\
& -\dot{z}_{b} \mid\left(\dot{z}-\dot{z}_{b}\right) \\
& \left.-k\left(z-z_{b}\right)\right) \\
& k_{2}=\left(\dot{z}+\frac{l_{1}}{2}\right) d t \\
& l_{2}=\frac{d t}{\left(m+\rho C_{a} V_{P}\right)}\left(-\frac{1}{2} \rho C_{d} A_{P} \mid(\dot{z}\right. \\
& \left.+\frac{l_{1}}{2}\right)-\dot{z}_{b} \mid\left(\left(\dot{z}+\frac{l_{1}}{2}\right)\right. \\
& \left.-\dot{z}_{b}\right) \\
& \left.-k\left(\left(z+\frac{k_{1}}{2}\right)-z_{b}\right)\right) \\
& k_{3}=\left(\dot{z}+\frac{l_{2}}{2}\right) d t \\
& l_{3}=\frac{d t}{\left(m+\rho C_{a} V_{P}\right)}\left(-\frac{1}{2} \rho C_{d} A_{P} \mid(\dot{z}\right. \\
& \left.+\frac{l_{2}}{2}\right)-\dot{z}_{b} \mid\left(\left(\dot{z}+\frac{l_{2}}{2}\right)\right. \\
& \left.-\dot{z}_{b}\right) \\
& \left.-k\left(\left(z+\frac{k_{2}}{2}\right)-z_{b}\right)\right) \\
& k_{4}=\left(\dot{z}+\frac{l_{3}}{2}\right) d t \\
& l_{4}=\frac{d t}{\left(m+\rho C_{a} V_{P}\right)}\left(-\frac{1}{2} \rho C_{d} A_{P} \mid(\dot{z}\right. \\
& \left.+\frac{l_{3}}{2}\right)-\dot{z}_{b} \mid\left(\left(\dot{z}+\frac{l_{3}}{2}\right)\right. \\
& \left.-\dot{z}_{b}\right) \\
& \left.-k\left(\left(z+\frac{k_{3}}{2}\right)-z_{b}\right)\right)
\end{aligned}
$$

In which $d t$ is the time step adopted for the simulation. After calculating the coefficients shown in Equations 11 through 18, it is then possible to calculate the position and velocity increment, as shown in Equations 19 and 20.

$$
\begin{gathered}
d z=\frac{\left(k_{1}+2 k_{2}+2 k_{3}+k_{4}\right)}{6} \\
d \dot{z}=\frac{\left(l_{1}+2 l_{2}+2 l_{3}+l_{4}\right)}{6}
\end{gathered}
$$

This process is repeated in each time step in order to obtain the new values of the manifold's position and velocity.

In the end of each cycle, the tension on the cable is calculated as shown in Equations 21 and 22.

$$
\begin{gathered}
T=k\left(L(t)-L_{i}\right) \text { if } L(t)>L_{i} \\
T=0 \text { if } L(t)<L_{i}
\end{gathered}
$$

In which $L(t)$ is the instantaneous length and $L_{i}$ is the initial length. Equation 22 will be used whenever $L(t)$ is larger than $L_{i}$ to avoid nonphysical negative tensions.

\section{Case Study}

In order to run the simulation, it is necessary to first possess the manifold's characteristics. These are given or reference data, and may be also treated as screened data inside an optimization process. On this work, the hydrodynamic coefficients were obtained through experiments previously performed by Andrade et al. (2020). These characteristics are shown in Table 1.

\begin{tabular}{cc}
\multicolumn{2}{c}{ Table 1 - Manifold's Characteristics } \\
\hline Mass [Kg] & 910903 \\
\hline Length [m] & 29.00 \\
\hline Width [m] & 17.80 \\
\hline Height [m] & 5.70 \\
\hline Ca & 2.2 \\
\hline Cd & 1.6 \\
\hline Cable's EA [N] & 630000000 \\
\hline
\end{tabular}

Submerged Volume $\left[\mathrm{m}^{3}\right] \quad 150$

Every simulation run has a total length of 240 seconds and the time step is 0.1 second.

\subsection{Test Matrix}

A total of six cases representing different combinations of environmental conditions and cable lengths were simulated using the simplified model. All of these six cases were previously simulated using the OrcaFlex software and were run as experiments at LOC, as presented by Andrade et al. (2020). The cases are shown in Table 2. 
Table 2 - Test Matrix

\begin{tabular}{cccc}
\hline Condition & Amp $[\mathrm{m}]$ & $\mathrm{T}[\mathrm{s}]$ & Depth $[\mathrm{m}]$ \\
\hline C1 & 1 & 6 & 100 \\
\hline C2 & 1 & 12 & 100 \\
\hline C3 & 1 & 8 & 200 \\
\hline C4 & 1 & 12 & 200 \\
\hline C5 & 1 & 8 & 460 \\
\hline C6 & 1 & 12 & 460 \\
\hline
\end{tabular}

Where Amp is the motion's amplitude on the top of the cable, $T$ is the wave period and Depth is the distance between the manifold and the top of the cable, which is effectively the cable's initial length.

\subsection{Verification}

The simplified model provides the position, velocity, and cable's tension time series to the user after each case is run. An interval between 150 and 200 seconds is chosen in order to calculate statistical parameters of the time series. This interval is chosen because the series are already in the steady state by this point of the simulation. The acceleration values are calculated as the first time-derivative of the velocity. The results are shown in Table 3.

\section{Verification and Validation}

After running all the analysis, the results are then compared to the ones shown by Andrade et al.

(2020) in order to validate them.

Table 3-Simplified Model Results

\begin{tabular}{ccccccc}
\hline & C1 & C2 & C3 & C4 & C5 & C6 \\
\hline Mean Force $[\mathrm{kN}]$ & 7762 & 7492 & 7264 & 7513 & 7378 & 7318 \\
\hline$\sigma$ Force $[\mathrm{kN}]$ & 7697 & 2221 & 5740 & 4239 & 1340 & 2597 \\
\hline Max Force $[\mathrm{kN}]$ & 19556 & 11129 & 15641 & 13511 & 9321 & 11090 \\
\hline Min Force $[\mathrm{kN}]$ & 0 & 3813 & 0 & 1239 & 5524 & 3740 \\
\hline Mean Acc $\left[\mathrm{m} / \mathrm{s}^{2}\right]$ & 0.05 & 0.01 & -0.01 & 0.01 & 0.00 & -0.02 \\
\hline$\sigma$ Acc $\left[\mathrm{m} / \mathrm{s}^{2}\right]$ & 1.04 & 0.29 & 0.77 & 0.56 & 0.18 & 0.35 \\
\hline Max Acc $\left[\mathrm{m} / \mathrm{s}^{2}\right]$ & 1.62 & 0.49 & 1.10 & 0.81 & 0.26 & 0.49 \\
\hline Min Acc $\left[\mathrm{m} / \mathrm{s}^{2}\right]$ & -1.31 & -0.48 & -1.03 & -0.83 & -0.26 & -0.49 \\
\hline
\end{tabular}

\subsection{Validation}

Andrade et al. (2020) presents three different results for each of these six cases. These results are obtained by different methods. The first method is a model developed using hydrodynamic derivatives, which is called the Maneuver Model by the authors. The second method is the internal native model of the OrcaFlex software. The third set of results was obtained through experiments performed at LOC. These comparisons are graphically shown in Figures 2 through 9.

\section{Mean Force Comparison}

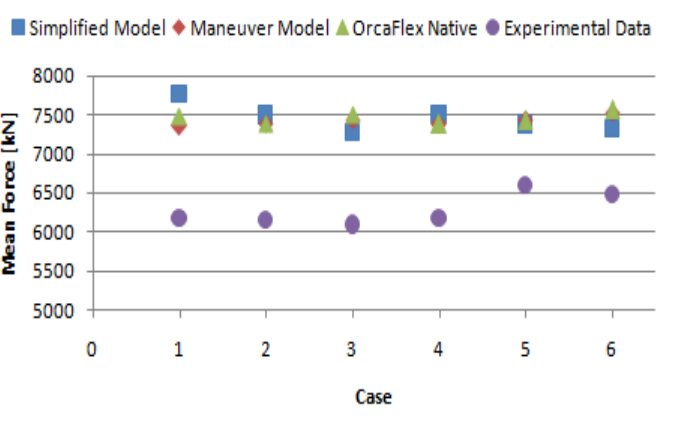

Figure 2 - Mean Force Results Comparison 


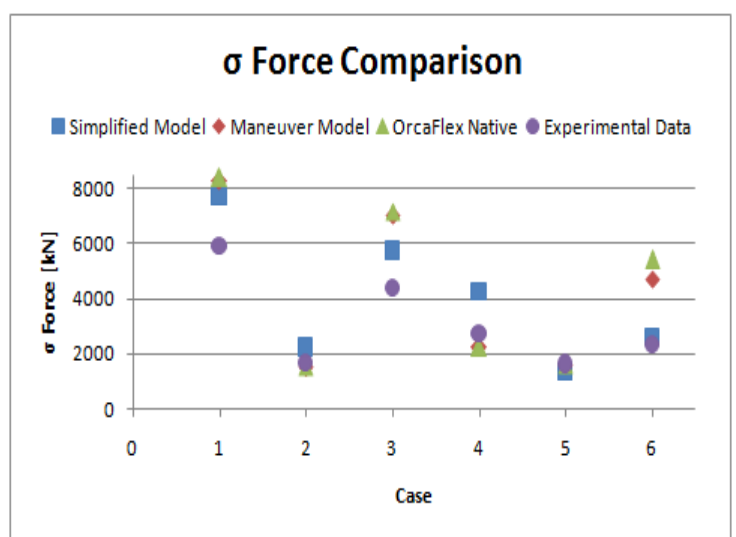

Figure 3 - Standard Deviation Force Results Comparison

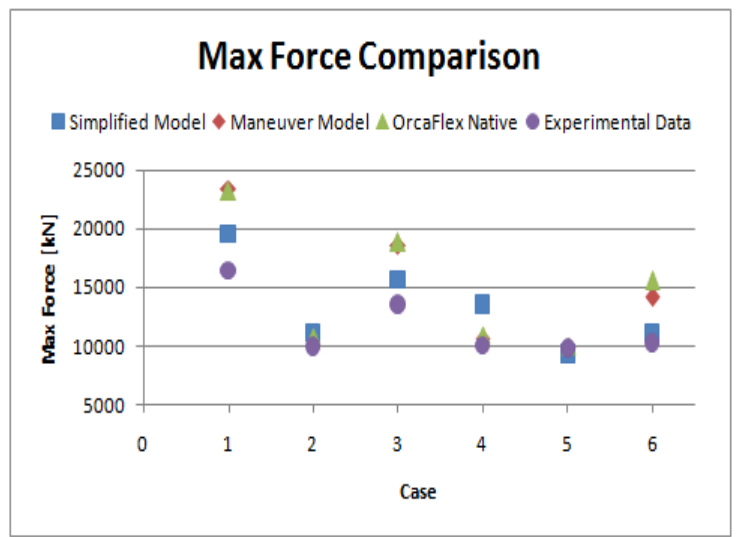

Figure 4 - Maximum Force Results Comparison

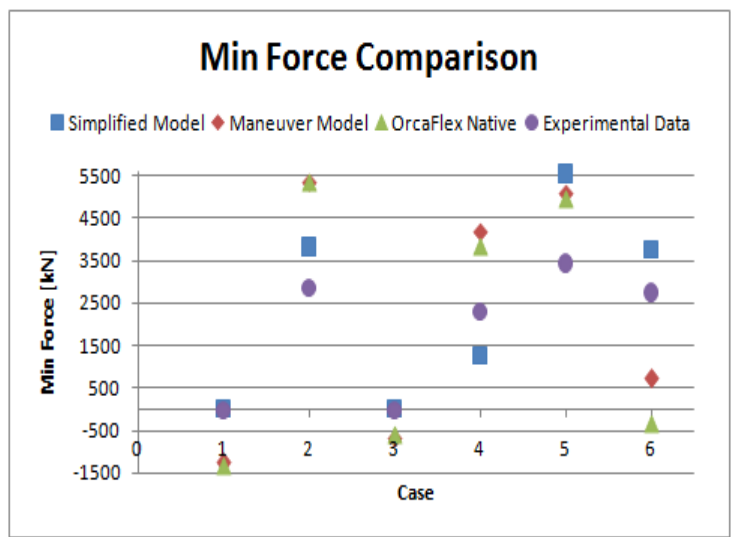

Figure 5 - Minimum Force Results Comparison

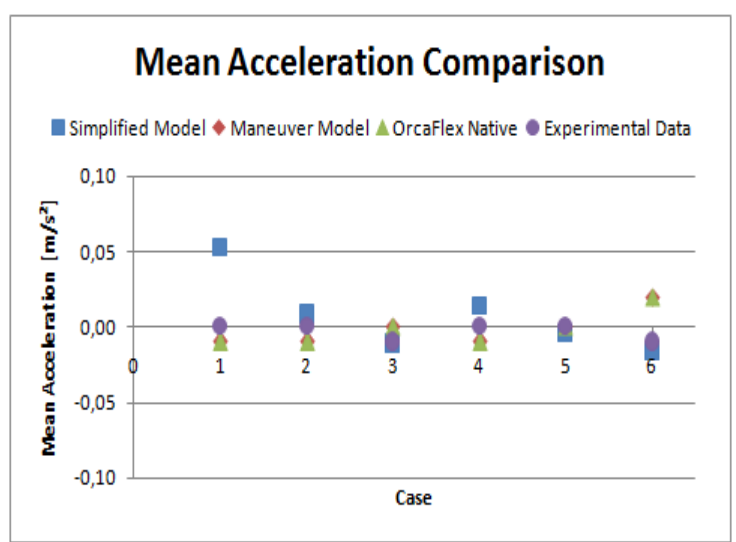

Figure 6 - Mean Acceleration Results Comparison

\section{$\sigma$ Acceleration Comparison}

- Simplified Model Maneuver Model $\triangle$ OrcaFlex Native Experimental Data

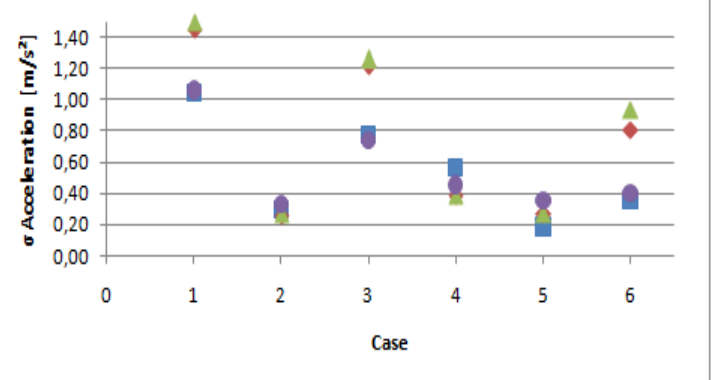

Figure 7 - Standard Deviation Acceleration Results Comparison

\section{Max Acceleration Comparison}

- Simplified Model $\$$ Maneuver Model $\triangle$ OrcaFlex Native Experimental Data

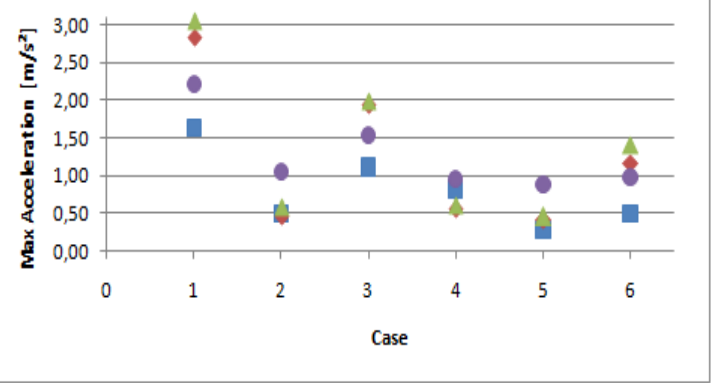

Figure 8 - Maximum Acceleration Results Comparison

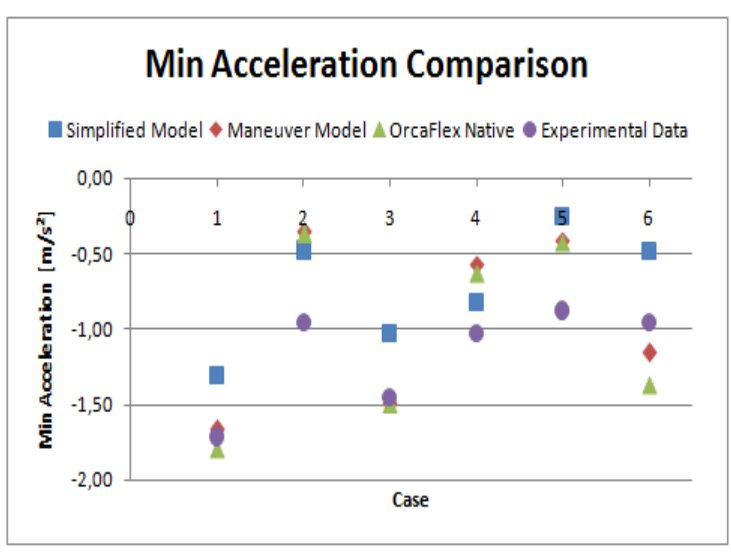

Figure 9 - Minimum Acceleration Results Comparison

Figure 2 shows that the Mean Force values obtained by the simplified model are very close to the ones obtained by the Maneuver Model and by the OrcaFlex native model. All these results are slightly higher than the ones obtained by experiments.

The standard deviation values of the force on the cable by the simplified model are also very close to the reference values, as can be seen in Figure 3 . Case 4 is the only one in which the values obtained 
by the simplified model are noticeably higher than the results obtained through the other methods.

The maximum force on the cable is an important result because it can indicate if the cable will break due to elevated tension values. Figure 4 indicates that the results obtained by the simplified model are closer to the experimental results than the numerical OrcaFlex results for most cases, the only exception being Case 4 again.

Figure 5 shows that the minimum force results of the simplified model are also usually closer to the experimental results than the OrcaFlex results, Case 5 being the only exception this time.

Considering the order of magnitude of the acceleration values, Figures 6 and 7 indicate that the mean acceleration and standard deviation are very similar for the three numerical procedures and for the experimental data.

Figure 8 shows that the maximum acceleration values obtained by the simplified model are usually lower than the reference values. On the other side, Figure 9 indicates that the minimum acceleration values are usually higher when using the simplified model. However, these values are still very close to the reference values.

\section{Fast Fourier Transform Results}

In order to compare the frequencies of the results obtained by the simplified model with those obtained by Andrade et al. (2020), the Fast Fourier Transforms of the force and acceleration time series were calculated. These results are shown in Figures 10 to 15.

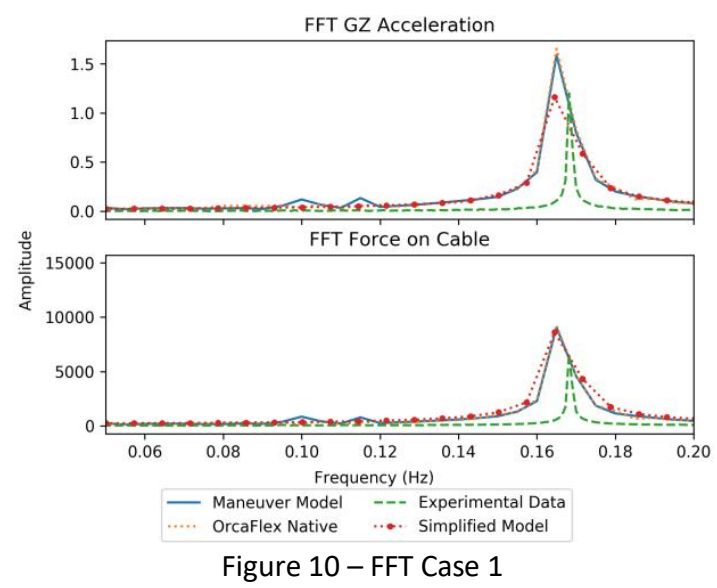

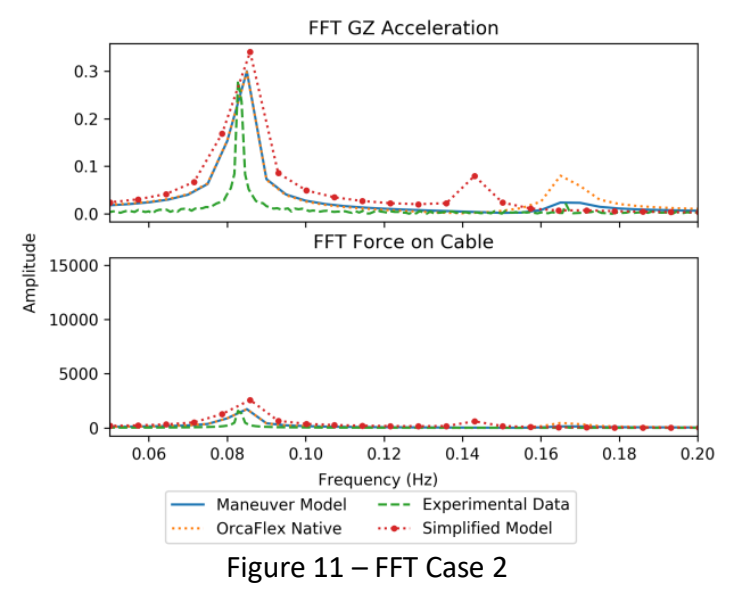
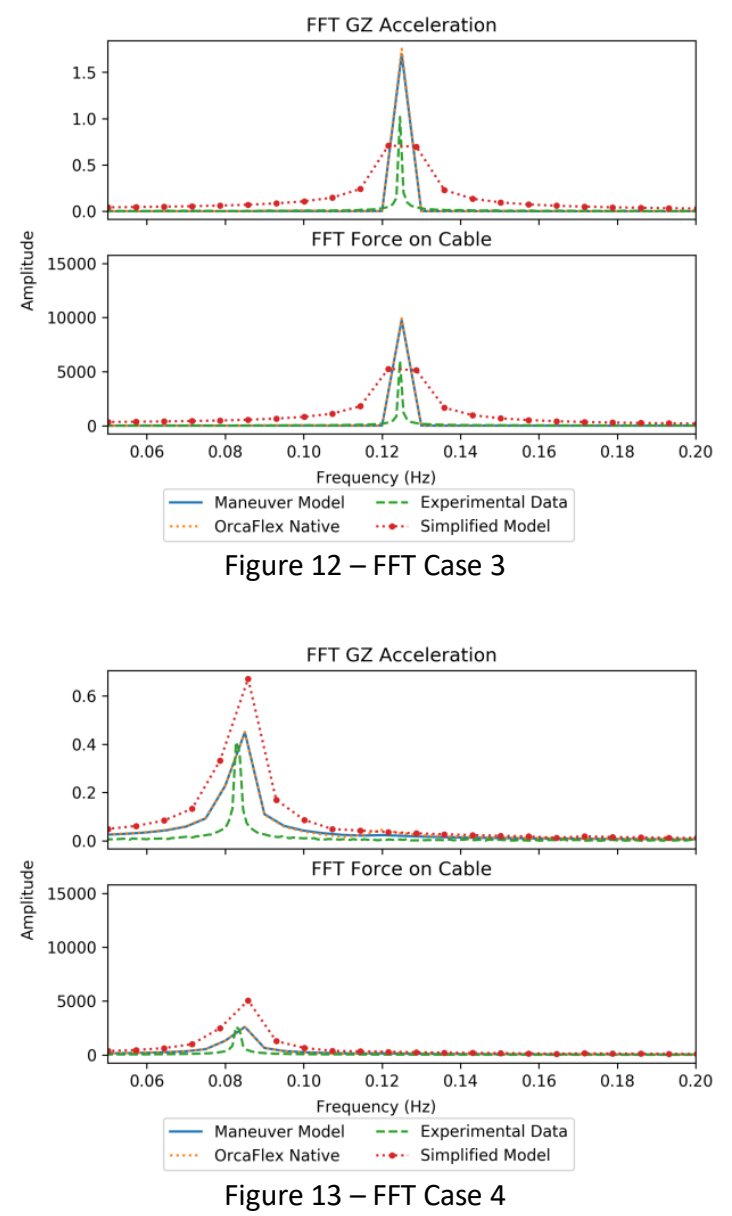


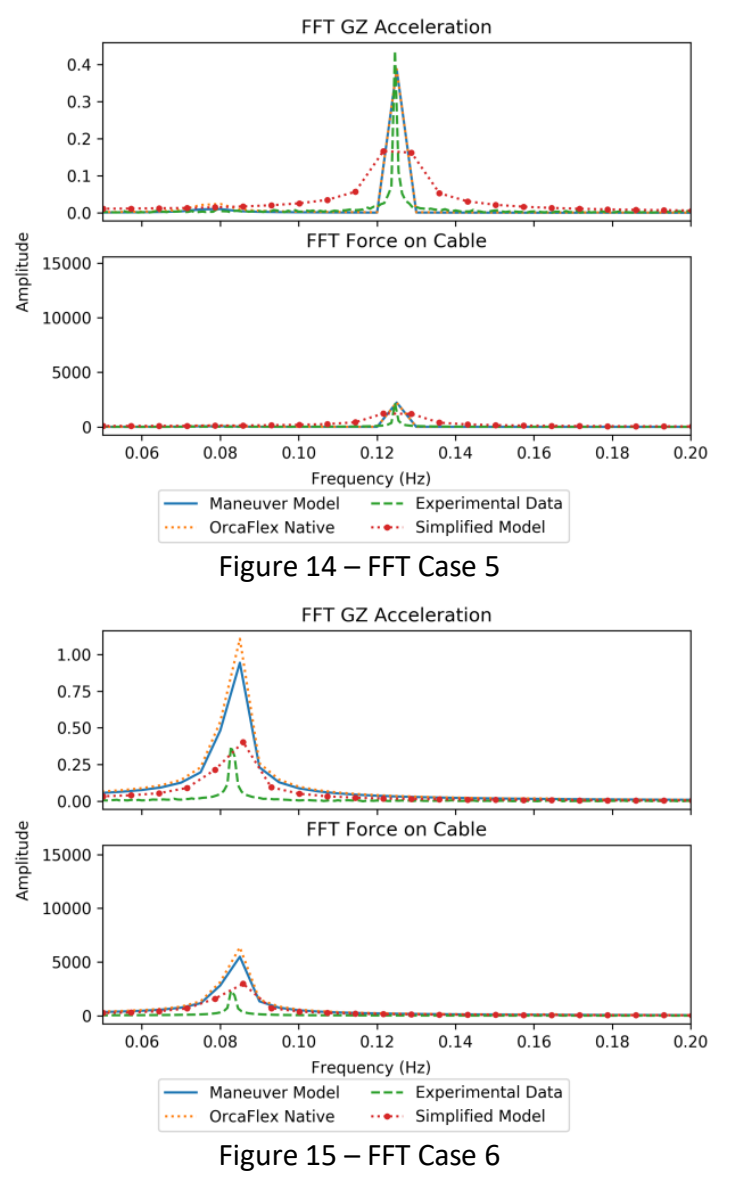

The components identified for the simplified model results are close to the numerical results obtained by Andrade et al. (2020) which are also similar to the experimental components, except for Case 2 (shown in Figure 11), in which the second frequency peak appears slightly displaced to the left. This may have occurred due to the assumptions adopted during the development of the simplified model. Another important point is that the main force and acceleration frequencies components are equal to the excitation frequency for each case.

\section{Conclusion}

Good adherence was found when comparing the results obtained by the use of the simplified model to those obtained by the native OrcaFlex Model, the Maneuver Model and experimental data. However, the simplified model still has limitations. A future implementation of more degrees of freedom in the model tends to result in lesser force values, because this implies that there is more energy dissipation.

In addition, as presented by Faltinsen (1990), there is a possibility that the drag and added mass coefficients change according to the Keulegan-
Carpenter (KC) number, so they would not be constant values. These studies do not consider any geometry similar to the manifold's geometry, so it is necessary to make further studies in order to determine that this effect also happens for this kind of geometry. If proven to be true, then it will be necessary to implement variable drag and added mass coefficients to the model in order to obtain better results.

\section{References}

ANDRADE, E. M.; SALES JR, J. S.; FERNANDES, A. C.; RIBEIRO, M. L.; TEIXEIRA, P. V. Time Domain Simulation of Subsea Equipments Installation Using Hydrodynamic Derivatives. OMAE, 2020.

FALTINSEN, O. M. Sea Loads on Ships and Offshore structures. 1 ed. Cambridge: Cambridge University Press, 1990.

JOURNÉE, J. M. J.; MASSIE, W. W. Offshore Hydromechanics. 1 ed. Delft University of Technology, 2001.

MARIANO, V. Avaliação de Métodos Numéricos Aplicada a Identificação de Parâmetros e de Perturbações Externas em Sistemas Mecânicos. Campina Grande: UFPB, 1998.

MORK, H.; LUNDE, J. A Cost-Effective and Safe Method for Transportation and Installation of Subsea Structures - The Pencil Buoy Method. Offshore Europe, Aberdeen, 2007.

RAO, S. Vibrações Mecânicas. 4 ed. São Paulo: Pearson Education, 2008.

ROVERI, F.; CERQUEIRA, M. B.; MACHADO, R. D. The Utilization of the Pendulous Motion for Deploying Subsea Hardware in Ultra-Deep-Water. Deep Offshore Technology XVII (DOT), Vitória, Brasil, 2005 November. 